\title{
General Discussion to the Papers of H. J. Hachen, Ulrich K. Banniza von Bazan \& Volkmar Paeslack, David J. E. Cheshire, George Hahn \& Robin Black, and G. M. Bedbrook
}

Dr D. BuRke (Australia). Mr Chairman, at the risk of an Australian takeover this morning with an Australian Chairman, one Australian speaker, a former Australian speaker and now an Australian discussant, I would like to make a few comments. I've always wanted to come to a meeting and say that I just happen to have a few slides in my pocket, and with your permission I would like to add a little bit to the information which has been mentioned by a number of speakers this morning. In particular, the reference to the common presentation of children with trauma with no bony injury and complete and major cord injuries, David Cheshire in particular developed this thing a little more in the possible pathology of these injuries. I happened to get my hands on two cases of infants in the last 2 months and I'd just like to very briefly show these now and ask for your comments. long.

DR Yeo (Chairman): David, they'll never ask me to be Chairman again if you talk too

DR D. BURKE. Both children came to post-mortem, one of them under my care and one not. The first child of 19 months of age, injured in a motor car accident in February this year, was treated at the Royal Children's hospital for the first month and then came to us at the Austin. He had a tetraplegia which was incomplete below C6, complete below C8, all X-rays including myelography were normal. He died at 3 months after the injury, and the surgical section of the spinal cord shows the very narrow segment rather like those that were mentioned earlier. There was no evidence of fracture or dislocation. At post-mortem there was some slight instability at $\mathrm{C}_{7}$ level, indicating perhaps some softening of the soft tissues in that region. The pathologist said that he considered the diagnosis was crush necrosis of the spinal cord possibly due to hyperextension injury, which is interesting in view of David's comments. I myself felt that it's more likely to be a longitudinal stretch injury than a hyperextension but perhaps the panel would like to comment on that.

The second child was a birth injury which was treated at a country hospital. It was a breech delivery and the child was brought down to Melbourne within 24 hours of diagnosis. It was not a difficult breech delivery apparently, there were no forceps used and I saw the patient briefly in consultation only. The child died only 3 days after birth. The post-mortem here showed the spinal cord completely severed at about C6 level, the clinical features were of a complete C6 tetraplegia. No bony injury on X-ray, and a lot of blood lying around the cord at the rupture point extending down into the lumbar region extra-durally. At the level of rupture it was subdural as well, and the child also had a ruptured tear of the tentorium with a lot of blood around the brain as well. The pathologist, Dr Gurly, at Queen Victoria Hospital where the post-mortem was done, is quite adamant that the diagnosis at post-mortem was an epidural and intradural cervical haemorrhage, a massive haemorrhage with compression of the spinal cord at $\mathrm{C}_{5} / 6$ causing rupture of the cord. His reason for saying this is that there was no blood inside the cord tissue at all. Therefore, it was a rupture of the cord by external compression and not ruptured by stretch hyperextension. This is Dr Gurly's opinion, I've argued this point with him. I personally don't agree, I think this is another example of stretch and possibly hyperextension. We do know the mechanism at least of most breech deliveries, whereas the first child I presented we do not know the mechanism, it was a car accident and that's all we know.

Dr. D. Cheshire (U.S.A.). I am being reminded by our Chairman that time is brief. For those of you who are interested I do most highly recommend the paper of I975 of Ahmann and his colleagues. These paediatric neurologists provided beautiful autopsy evidence of the cord. I wish that they had included a description or a picture of the spine as in David's first slide, because you cannot put the picture together by looking 
at the cord without looking at the spine. The only other thing I would like to say is that I personally would like an expression of opinion from this assembled body for you to take back to the pathologist at the Queen Victoria Hospital in Melbourne to state that we are not altogether in agreement with his findings.

Mr P. HARRIS (G. B.). I'd like to mention to Dr Bazan that laminectomy should not produce any spinal deformity unless the articular joints have been damaged. Secondly the point of scoliosis in these children and the inbalance of the motor paralysis, this has been shown experimentally. We did this some years ago also in Edinburgh with Professor James. You can produce scoliosis and you can rectify it as was mentioned, by producing paralysis of the other muscles to balance up. There's the point about fixing the spine.

George Bedbrook; about operating on children's spines, fusing the spines at any time especially if they're young in relation to subsequent growth of the spine. The only one case I dealt with about 3 or 4 weeks ago was a child of about 9 with a head injury and very restless. The child had a $\mathrm{C}_{2} / 3$ fracture dislocation with minimal neurological changes. I simply exposed the spinal column posteriorly and put in some methylnebatulate and fused that area and the child was up and about the following day. Now what is the future of this child, Dr Bedbrook. The child is aged 9, the spine has been fused at $\mathrm{C} 2 / 3$ level, what will happen with growth?

DR VON BAZAN. Mr Harris, I didn't exactly understand your question concerning laminectomy, maybe you have misunderstood me. I didn't say laminectomy wouldn't produce any spinal deformity, I meant the opposite. The laminectomy done for spinal tumours is in our opinion and experience, most often a reason, for scoliosis or for kyphotic deformity.

DR BEDBROoK. First of all I should like to answer Phillip Harris's comments. I can't agree with him that laminectomy not involving the articular facets will not cause scoliosis, this is not true. It may not cause scoliosis to a very marked condition, but it will cause kyphosis, which is a much more serious condition and, in fact, I have in the wards at the present time a child who had an extensive laminectomy for a histiocytoma involving the extradural canal at $\mathrm{T}_{4}$ at the age of 4 , and there was no doubt that the laminectomy was required but the articular facets were not involved. I progressively watched that child over the last Io years, not being able to manage him, becoming severely kyphotic. It was only when he became paraplegic, as we had warned the paediatrician that he would, that he was ultimately handed over for management. The problem of this child's deformity could have been prevented with an adequate bracing. There is no doubt that whether you remove the articular facets or not does not prevent scoliosis, and this is quite definite as far as pathology is concerned. Now as far as the time of surgery in these children is concerned, this matter is one of great concern. 75 per cent of bone growth in the spinal canal and spinal column will be completed by the age of 12 years and therefore most of us try not to operate on these children until after the age of 12 , it is very rarely that we have to operate on them before that time. A localised fusion of the type $\mathrm{Mr}$ Harris indicated at $\mathrm{C}_{2} / 3$ will have no effect on bone growth whatsoever, that area will simply stop growing, the rest of the spinal column will go on growing, but I must disagree with the use of methacolade in the spinal column. It's foreign material, we don't know what will happen over a long period of time. If it's necessary to fuse such a child at that age, and I would be very much against this, I see no reason for it at all, I feel I could manage that child without such fusions, then bone is undoubtedly the best method of fusion.

Dr Masalawala (India). My only brief comment is to Dr Hachen and to Dr Cheshire in reference to the second case. Neither of them have explicity mentioned that they were X-rayed in flexion, extension and neutral position and even with tomograms. Some of their children, especially the flexion injuries which recovered, may have been injuries in that region.

DR YEO. Thank you very much, ladies and gentlemen. Would you please join me very enthusiastically and thank our speakers this morning. 